\title{
Avaliação do potencial angiogênico do plasma rico em plaquetas no ligamento suspensor do boleto de equinos
}

Gustavo Gonçalves Parisi, Mariana Lopes da Conceiçao, Vitor Hugo Santos, Jaqueline Brandão de Souzä, Carlos Eduardo Fonseca Alves, João Pedro Hübbe Pfeifer, Marina Landim e Alvarenga, Gustavo dos Santos Rosa, Betsabéia Heloísa Gentilha Milani, Ana Liz Garcia Alves

Faculdade de Medicina Veterinária e Zootecnia, Universidade Estadual Paulista (UNESP), Botucatu, SP, Brasil

*Autor correspondente

e-mail: jaquelinebrandao.s@hotmail.com

\section{Resumo}

O plasma rico em plaquetas (PRP) consiste em uma alta concentração de plaquetas em um pequeno volume de plasma, em média quatro vezes maior do que a concentração sérica, sendo esta concentração obtida através do método de dupla centrifugação. O PRP tem sido utilizado como um catalisador no que diz respeito à cicatrização de vários tecidos, como o epitelial, muscular, ósseo, tendíneo, ligamentar e condral, além de ser utilizado também para cultivos celulares, apresentando um efeito reparativo, angiogênico, aumentando a migração e diferenciação celular. Exerce seu efeito biológico através de seu rico conteúdo de fatores de crescimento. 0 uso deste biocomposto é destacado em cavalos atletas, já que nesses animais as lesões ligamentares são comuns e comprometem seriamente o seu desempenho. O PRP tem um custo relativamente baixo e é de fácil obtenção e uso, entretanto sua efetividade ainda é discutida. Considerando estes aspectos supracitados, este trabalho teve como objetivo avaliar os efeitos angiogênicos do PRP no tecido ligamentar in vivo, assim como mensurar a concentração de VEGF-A no PRP. 0 biocomposto foi processado pelo método de centrifugação dupla, com $20 \mathrm{~mL}$ de sangue total coletado na veia jugular em tubo de citrato de sódio a 3,8\% (BD Vacutainer ${ }^{\circledR}$ ), utilizando a primeira centrifugação a $300 \mathrm{~g}$ por cinco minutos, retirando todo o plasma, sem porcentagem de descarte e desprezando o buffy coat. Em seguida, foi realizada uma segunda centrifugação a 700g por 15 minutos, sendo a zona de descarte de 75\%. 0 restante foi delicadamente homogeneizado, consistindo o PRP. A manipulação do plasma foi realizada em temperatura controlada e câmara de fluxo laminar. O PRP foi administrado no ligamento suspensor do boleto de equinos hígidos, que foram submetidos a avaliações ultrassonográficas e de Power Doppler, realizadas nos primeiros sete dias após o tratamento e semanalmente até a biópsia. 0 histopatológico foi realizado de amostras ligamentares através de biópsia, 30 dias após a aplicação do PRP, para verificação da formação de neovasos. O PRP 
obteve uma quantidade significativamente maior de VEGF-A em $25 \%$ das amostras $(\mathrm{P}<0,05)$, observado no teste de ELISA, quando comparado ao plasma não processado. 0 exame histopatológico mostrou um número consideravelmente maior de vasos sanguíneos nas lâminas feitas a partir do ligamento do grupo tratado quando comparado ao controle. Observamos que o PRP é um biomaterial capaz de estimular a neovascularização, sendo, portanto, um bom catalisador para a reparação do ligamento suspensor do boleto, mostrando-se uma alternativa viável para o tratamento de desmites no ligamento avaliado. Este trabalho foi aprovado pela Comissão de Ética no Uso de Animais (CEUA) da Faculdade de Medicina Veterinária e Zootecnia da UNESP (Protocolo 19/2015) de Botucatu.

Palavras-chave: Plasma rico em plaquetas. Equinos. Fatores de crescimento. 